CECÍlio FILHO AB; MAY A; PÔRTO DRQ; BARBOSA JC. 2009. Crescimento da cebola em função de doses de nitrogênio, potássio e da população de plantas em semeadura direta. Horticultura Brasileira 27: 049-054.

\title{
Crescimento da cebola em função de doses de nitrogênio, potássio e da população de plantas em semeadura direta
}

\author{
Arthur Bernardes Cecílio Filho ${ }^{1}$; André $\mathrm{May}^{2}$; Diego RQ Porto ${ }^{1}$; José Carlos Barbosa ${ }^{1}$ \\ ${ }^{1}$ UNESP-FCAV, Rodov. Prof. Paulo D. Castellane s/n, 14884-900 Jaboticabal-SP; ${ }^{2}$ IAC, C. Postal 28, 13012-970 Campinas-SP; \\ rutra@fcav.unesp.br; amay@iac.sp.gov.br
}

\begin{abstract}
RESUMO
O trabalho realizado em São José do Rio Pardo, de 07/03 a 08/08/ 04 teve o objetivo de avaliar o efeito de doses de nitrogênio e de potássio e populações de plantas no acúmulo de matéria seca da parte aérea e do bulbo de duas cultivares de cebola. O delineamento experimental utilizado foi de blocos ao acaso, com 4 repetições, com os tratamentos em esquema fatorial $2 \times 4 \times 4$ × 4 : cultivares (Híbridos Optima e Superex), nitrogênio $\left(0 ; 50 ; 100\right.$ e $\left.150 \mathrm{~kg} \mathrm{ha}^{-1} \mathrm{de} \mathrm{N}\right)$, potássio $\left(0 ; 75 ; 150\right.$ e $225 \mathrm{~kg} \mathrm{ha}^{-1}$ de $\left.\mathrm{K}_{2} \mathrm{O}\right)$ e população de plantas $(60 ; 76$; 92 e 108 plantas $\mathrm{m}^{-2}$ ). Houve efeito significativo dos fatores isoladamente. Na colheita a cv. Optima apresentou maiores quantidades de matéria seca da parte aérea (MSPA) e de matéria seca de bulbo (MSB) que a cv. Superex. A aplicação de nitrogênio promoveu incrementos significativos na MSPA e MSB. A influência do K na MSPA não foi tão expressiva quanto a observada para o nitrogênio, mas de modo semelhante a este incrementou o acúmulo de MSB. O aumento da população de plantas reduziu a MSPA e consequentemente a MSB. As equações de acúmulos de MSPA e de MSB das cultivares, em reposta às doses de N e K e população de plantas, não diferiram entre si.
\end{abstract}

Palavras-chave: Allium cepa L., fertilização, densidade populacional, cultivar.

\begin{abstract}
Accumulation of dry mass in onion depending on nitrogen, potassium and plant population in direct sowing

The effects of nitrogen and potassium fertilizer doses were evaluated on the growth of two onion cultivars, grown in different plant populations. The experiment was carried out in São José do Rio Pardo in an onion production area in São Paulo State, Brazil, from $03 / 07$ to $08 / 08 / 04$. The experimental design was of blocks with four replications in a $2 \times 4 \times 4 \times 4$ factorial cheme: cultivars (Hybrids Optima and Superex), nitrogen $\left(0 ; 50 ; 100\right.$ and $\left.150 \mathrm{~kg} \mathrm{ha}^{-1} \mathrm{~N}\right)$, potassium $\left(0 ; 75 ; 150\right.$ and $\left.225 \mathrm{~kg} \mathrm{ha}^{-1} \mathrm{~K}_{2} \mathrm{O}\right)$ and plant populations $\left(60 ; 76 ; 92\right.$ and 108 plants $\left.\mathrm{m}^{2}\right)$. There was significant effect on the factors separately. At the end of the cycle, the cv. Optima presented larger quantities of dry matter in the aerial parts (APDM) and in the bulbs (BDM). The application of nitrogen promoted significant increments in APDM and BDM. The influence of K on APDM was not as expressive as in relation to that observed for the nitrogen, but similarly to this, it increased the accumulation of BDM. The increase of the population of plants reduced the APDM and consequently the BDM. The equations of accumulation of APDM and of BDM, of both cultivars, obtained as the response to the doses of $\mathrm{N}$ and $\mathrm{K}$ and population of plants, didn't differ from each other.
\end{abstract}

Keywords: Allium cepa L., fertilization, plant density, cultivar.

(Recebido para publicação em 20 de novembro de 2007; aceito em 19 de janeiro de 2009)

(Received in November 20, 2007; accepted in January 19, 2009)

$\mathrm{N}$ o Brasil, a cebola é considerada a terceira hortaliça mais importante em valor econômico, superada apenas pela batata e tomate. É consumida preferencialmente na forma in natura em saladas, sendo também utilizada para temperos e condimentos. O consumo per capita brasileiro situa-se próximo de $4,7 \mathrm{~kg}$ por ano, enquanto na Argentina este valor é de $10,0 \mathrm{~kg}$, no Uruguai, 7,7 $\mathrm{kg}$ e no Paraguai, 7,0 kg (Boeing, 2002). O munícipio de São José do Rio Pardo é tradicional produtor de cebola, predominando o sistema de transplante de mudas, com produtividades que raramente atingem $50 \mathrm{t} \mathrm{ha}^{-1}$ de bulbos ${ }^{1}$.
Entre muitos fatores que influenciam o crescimento e a produtividade da cultura da cebola estão a densidade populacional e a nutrição da planta. No primeiro caso, com o aumento do número de plantas por área, há modificação no crescimento em razão da maior competição pelos fatores do meio. Reduções na produção de matéria seca da parte aérea e do bulbo foram observadas quando elevou-se a densidade de plantio (Kanton et al., 2002; Resende \& Costa, 2005).

O adensamento da cultura da cebola tem sido testado pelos produtores rurais de forma empírica, porém obtendo- se aumentos significativos de produtividade. No entanto, Fontes (2002) alerta que os trabalhos científicos que comprovam as novas tecnologias adotadas visando incrementos na produtividade, ainda são escassos.

Com relação à nutrição da cebola, o nitrogênio e o potássio destacam-se. $\mathrm{O}$ $\mathrm{N}$ é o segundo nutriente, em quantidade, presente na planta; superado apenas pelo K (Vidigal, 2000; Pôrto et al., 2007). Loué (1978) reporta várias pesquisas que constataram interação significativa entre nitrogênio e potássio na produtividade de culturas formadoras de órgãos de reserva subterrâneo.

${ }^{1}$ Breda Junior, JM (Cooperativa dos cafeicultures de Guaxupé, Filial São José do Rio Pardo) Informação pessoal, 2005. 


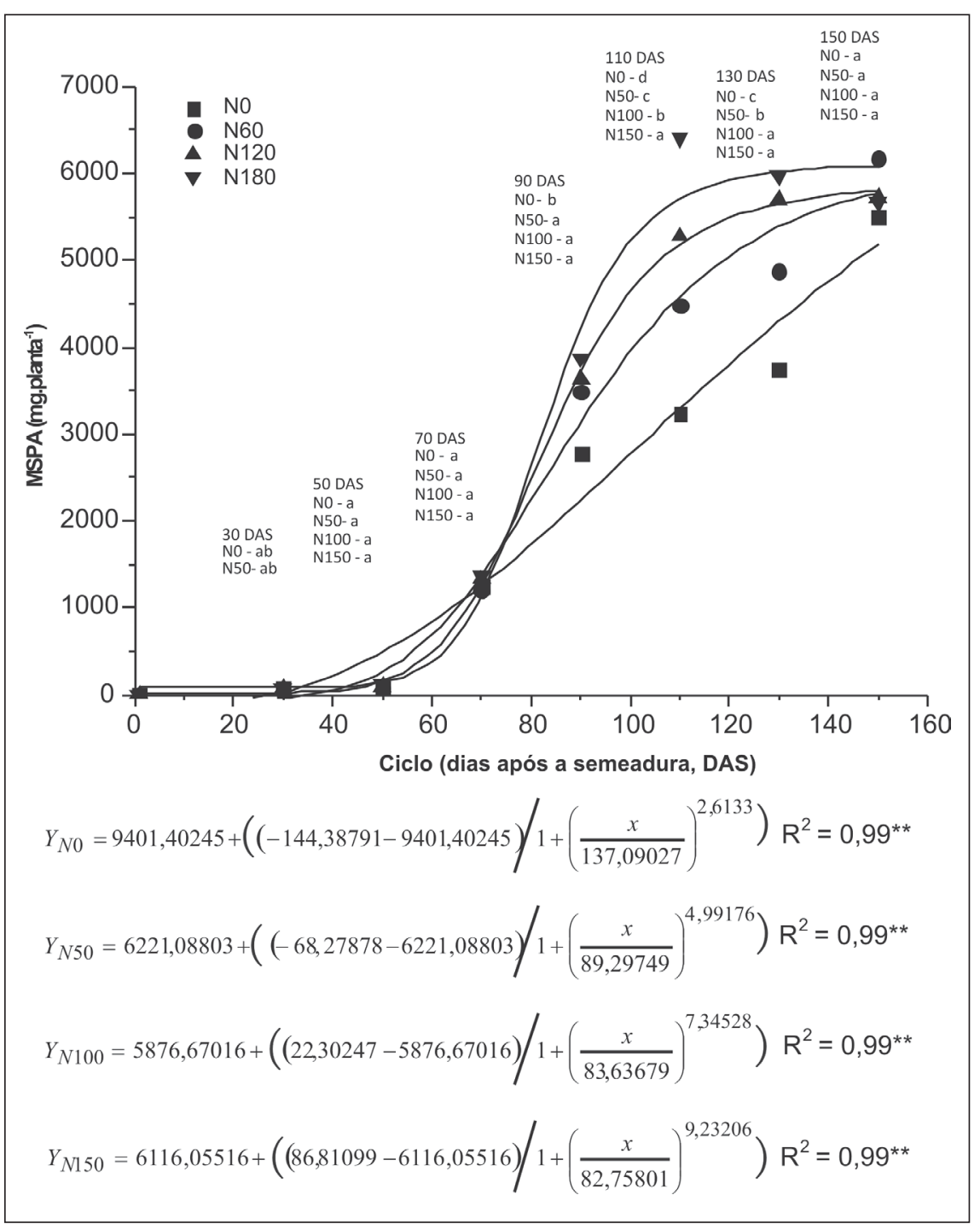

Figura 1. Acúmulo de matéria seca da parte aérea (MSPA) de plantas de cebola no decorrer do ciclo, em função da dose de nitrogênio aplicada. (aerial part dry mass (MSPA) of onion plants in elapsing of the cycle, in function of the dose of nitrogen applied). Jaboticabal, UNESP, 2006.

Mengel \& Kirkby (1987) relatam que as culturas apresentam respostas menores na produtividade quando se têm incrementos somente nos níveis de nitrogênio, do que quando quantidades satisfatórias de fósforo e potássio são aplicadas.

Resultados de pesquisa sobre estes fatores e suas interações, no Brasil, restringem-se a culturas estabelecidas por transplante de mudas. Contudo, vem sendo crescente o emprego do método de semeadura direta, visto que, segundo Guimarães et al. (1997), esta técnica pode proporcionar redução de $21 \%$ no custo de produção da cultura, principalmente, devido à economia de mão-de-obra. Além disso, os autores relatam que, em grande latitude Sul de 21'37'16", longitude Oeste $46^{\circ} 53^{\prime} 15^{\prime \prime}$ e altitude de aproximadamente $900 \mathrm{~m}$.

O clima da região é do tipo tropical com inverno seco, classificado como Aw segundo Köppen, descrito por Vianello \& Alves (1991). A precipitação pluvial média anual situa-se em torno de 1.400 $\mathrm{mm}$, e as temperaturas médias anuais máxima e mínima são de $31,6^{\circ} \mathrm{Ce} 17,9^{\circ} \mathrm{C}$, respectivamente.

O delineamento experimental utilizado foi de blocos ao acaso, com os tratamentos em esquema fatorial $2 \times 4 \times 4 \times 4$, com quatro repetições. Os fatores avaliados foram: cultivares (Híbridos Optima e Superex); populações de plantas (60; 76; 92 e 108 plantas $\left.\mathrm{m}^{-2}\right)$; doses de nitrogênio $\left(0,50,100\right.$ e $\left.150 \mathrm{~kg} \mathrm{ha}^{-1} \mathrm{de} \mathrm{N}\right)$ e doses de potássio $(0 ; 75 ; 150$ e $225 \mathrm{~kg}$ $\mathrm{ha}^{-1} \mathrm{de}_{2} \mathrm{O}$ ). As parcelas foram localizadas em canteiros de 1,2 $\mathrm{m}$ de largura, com cinco linhas longitudinais ao canteiro e com comprimento de $2,5 \mathrm{~m}$. O espaçamento entre linhas foi de $27,5 \mathrm{~cm}$.

O solo da área do experimento é classificado como um Latossolo Vermelho Amarelo de textura argilosa (Embrapa, 1999). A análise do solo da profundidade de 0 a 0,2 m revelou $\mathrm{pH}$ em $\mathrm{CaCl}_{2}$ de 5,2 e $25 \mathrm{~g} \mathrm{dm}^{-3}$ de matéria orgânica, além de $24 \mathrm{mg} \mathrm{dm}^{-3}$ de P-resina. Os teores de $\mathrm{K}, \mathrm{Ca}, \mathrm{Mg}$ e $\mathrm{H}+\mathrm{Al}$ foram, respectivamente, 1,$4 ; 31 ; 10$ e $28 \mathrm{mmol}_{\mathrm{c}} \mathrm{dm}^{-3} \mathrm{e}$ a CTC foi de $70,4 \mathrm{mmol}_{\mathrm{c}} \mathrm{dm}^{-3}$.

Com base na análise de solo feita em laboratório da UNESP-FCAV, Campus de Jaboticabal e segundo recomendações de Trani et al. (1996) para a calagem e adubação da cultura da cebola, sistema de transplantio, fez-se aplicação de calcário, um mês antes da semeadura, para elevar a saturação por bases a $70 \%$. Aplicou-se na semana da instalação do experimento, $300 \mathrm{~kg} \mathrm{ha}^{-1}$ de $\mathrm{P}_{2} \mathrm{O}_{5}$, como superfosfato simples, à lanço e em área total, e 1,5 $\mathrm{kg} \mathrm{ha}^{-1}$ de $\mathrm{B}$, empregando bórax.

Dois dias antes da semeadura foram aplicados $30 \mathrm{~kg} \mathrm{ha}^{-1}$ de $\mathrm{Ne} 40 \mathrm{~kg} \mathrm{ha}^{-1} \mathrm{de}$ $\mathrm{K}_{2} \mathrm{O}$ em todos os tratamentos, exceto na testemunha. A incorporação foi feita com auxílio de enxada, seguida de irrigação com lâmina de $10 \mathrm{~mm}$. O restante do nitrogênio e potássio de cada tratamento foi parcelado em quantidades iguais e aplicado aos 30, 45 e 60 dias após a se- 
meadura. Foram empregados os fertilizantes, nitrato de amônio e cloreto de potássio.

A semeadura das cultivares Optima e Superex foi feita de 07 a 09/03/04, diretamente em canteiros com cinco linhas de plantio, em pequenas covas de $1 \mathrm{~cm}$ de diâmetro e $1 \mathrm{~cm}$ de profundidade, abertas com auxílio de um marcador de estrutura em ferro, gabaritado para as dimensões e espaçamentos desejados, distribuindo-se 5 a 7 sementes/cova. A emergência das plântulas iniciou-se em 17/03/04 e aproximadamente 15 dias após, fez-se o desbaste para estabelecer o número correto de plantas em cada parcela, de acordo com o fator população de plantas.

A aplicação de herbicidas, fungicidas e inseticidas foi feita de acordo com a necessidade da cultura. As irrigações foram diárias durante as primeiras semanas após a semeadura e a cada quatro dias em complementação às precipitações pluviais, nos períodos subsequientes, sendo utilizado o sistema de aspersão convencional, com a aplicação de uma lâmina média de $10 \mathrm{~mm}$.

Plantas foram colhidas a partir de 30 dias após a semeadura, em intervalos de 20 dias até a colheita final (27/07 a 08/08/ 04), quando $70 \%$ das plantas da parcela encontravam-se estaladas (amolecimento do pseudocaule e tombamento da parte aérea). As plantas foram arrancadas e deixadas sobre os canteiros com as folhas distribuídas sobre os bulbos para que ficassem protegidos da radiação direta. Após quatro dias no campo, os bulbos foram encaminhados ao laboratório e feitas as avaliações.

A matéria seca da parte aérea e do bulbo, expressas em mg planta $^{-1}$, foram secas em estufa com circulação forçada de ar quente a $65^{\circ} \mathrm{C}$, por $96 \mathrm{~h}$. Os bulbos foram picados para acelerar o processo de secagem, na estufa.

Os dados foram analisados estatisticamente através de análise de variância (teste F) segundo o delineamento proposto, pelo programa estatístico ESTAT (UNESP-FCAV, Campus Jaboticabal).

Para as regressões polinomiais, os modelos de regressão (linear, quadrático ou cúbico) foram escolhidos pelo maior coeficiente de determinação $\left(\mathrm{R}^{2}\right)$ que tenha apresentado maior significância pelo teste F.

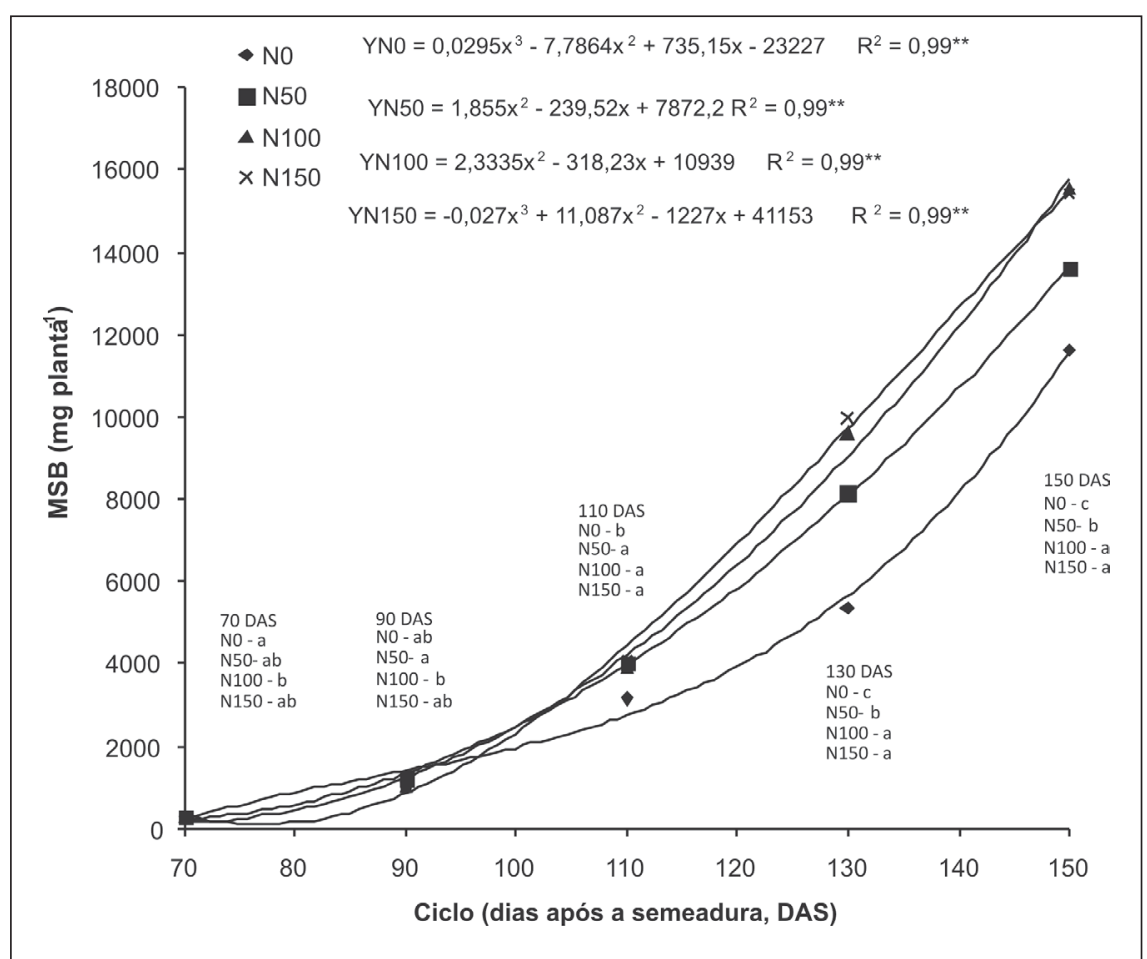

Figura 2. Acúmulo de matéria seca do bulbo (MSB) de plantas de cebola no decorrer do ciclo, em função da dose de nitrogênio aplicada. (bulb dry mass (MSB) of onion plants in elapsing of the cycle, in function of the dose of nitrogen applied). Jaboticabal, UNESP, 2006.

O acúmulo de matéria seca da parte aérea ao longo do ciclo foi ajustado ao modelo Logístico não linear, por meio do programa gráfico Origin 6.0:

$$
Y \quad a_{2} \frac{a_{1} a_{2}}{1{\frac{x}{x_{0}}}^{p}}
$$

Onde,

$a_{1}=$ valor inicial (assíntota inferior), ou seja, o valor mínimo da variável Y; $a_{2}$ = valor final (assíntota superior), ou seja, o valor máximo que a variável Y irá atingir; $x_{0}=$ centro $($ valor de $\mathrm{X})$ cujo $\mathrm{Y}=\left(\mathrm{a}_{1}\right.$ $\left.+\mathrm{a}_{2} / 2\right) ; p=$ potência (relacionada com a taxa de crescimento da variável Y).

$\mathrm{O}$ acúmulo de matéria seca do bulbo ao longo do ciclo foi ajustado a equações de regressão polinomial.

\section{RESULTADOS E DISCUSSÃO}

Houve efeito significativo para os fatores isolados nas diferentes datas de coleta, mas não houve interação entre os fatores estudados para a característica massa seca da parte aérea. Assim, as curvas que descrevem a evolução das caracterís- ticas ao longo do ciclo foram elaboradas em função de cada fator avaliado.

Para massa seca da parte aérea, houve efeito significativo para o fator cultivares aos 50, 110 e 150 dias após a semeadura (DAS). Nestas épocas, a massa seca da parte aérea (MSPA) da cv. Optima foi 0,44, 5,08 e 6,19 g planta $^{-1}$, respectivamente; enquanto a 'Superex', apresentou nas mesmas épocas 0,52, 4,63 e 5,47 $\mathrm{g} \mathrm{planta}^{-1}$, respectivamente. Para massa seca do bulbo (MSB), houve efeito significativo do fator cultivares somente aos 70 e 150 dias após a semeadura. A 'Optima' apresentou 0,28 e 14,77 g planta ${ }^{-1}$, respectivamente aos 70 e 150 DAS, enquanto a 'Superex' apresentou 0,24 e 13,52 g planta $^{-1}$ de MSB, nas mesmas datas. Assim, a 'Optima' terminou o ciclo com maior crescimento vegetativo, que refletiu positivamente em maior massa do bulbo.

Quanto ao efeito da adubação nitrogenada, até 70 DAS não foi verificada diferença significativa na quantidade de MSPA da cebola nas diferentes doses de $\mathrm{N}$ aplicadas (Figura 1). Nesta época, as plantas encontravam-se com 19,56 a 24,01\% do total acumulado no final do ciclo. 


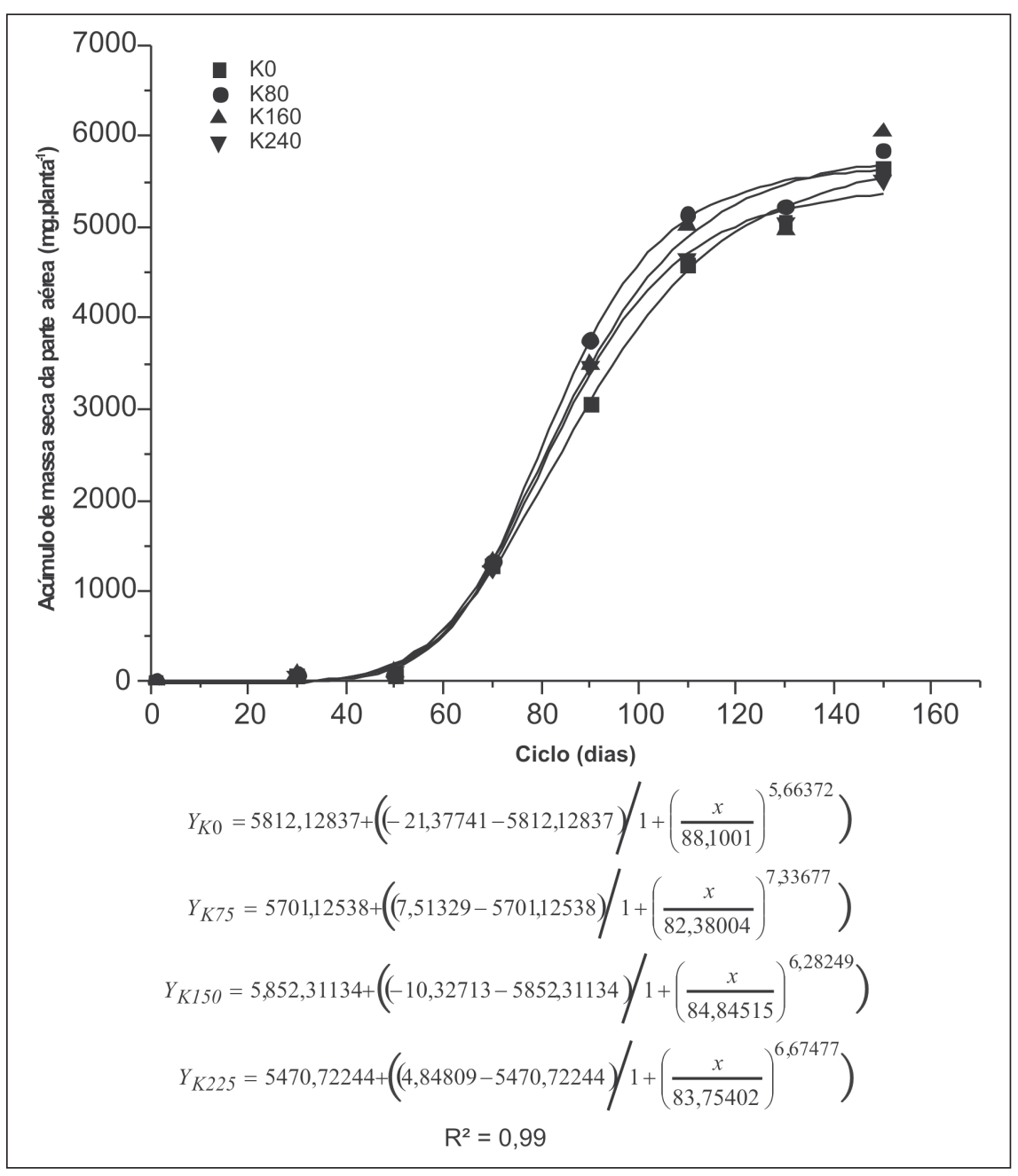

Figura 3. Acúmulo de massa seca da parte aérea de plantas de cebola no decorrer do ciclo, em função da dose de potássio aplicada. (aerial part dry mass (MSPA) of onion plants in elapsing of the cycle, in function of the dose of potassium applied). Jaboticabal, UNESP, 2006.

A partir de 70 DAS, os incrementos percebidos na MSPA da cebola foram diferenciando-se em função da dose de $\mathrm{N}$ (Figura 1). Aos 90 DAS, as plantas adubadas com $\mathrm{N}$ não diferiram entre si, mas o foram da testemunha (dose zero de N). Contudo, aos 110 DAS, as doses proporcionaram acúmulo de MSPA distintas, que no final do ciclo voltaram a não diferir até mesmo da dose $0 \mathrm{~kg} \mathrm{ha}^{-1}$ (Figura 1).

A cebola tem crescimento lento até próximo à metade do ciclo (Haag et al., 1970; Wiedenfeld, 1994; Vidigal et al., 2002). Tei et al. (1996), avaliando o crescimento de cebola em sistema de semeadura direta, verificaram que o acúmulo médio de massa seca de três cultivos foi de 4,4 $\mathrm{g} \mathrm{planta}^{-1}$ até próximo dos 40 dias após a emergência (DAE) e que no final do ciclo, 150 DAE, o acúmulo médio de dia entre 120 a 150 DAS. Nota-se que quanto maior a dose de $\mathrm{N}$ a planta apresentou mais precocemente desaceleração no acúmulo de MSPA (Figura 1). Essa desaceleração pode ser explicada pelo acúmulo de MSB, que foi muito mais intenso em plantas fertilizadas do que em não fertilizadas e tanto mais intenso quanto maior a dose de $\mathrm{N}$. A partir de 110 DAS, a MSB em plantas não fertilizadas com $\mathrm{N}$ foi menor do que nas fertilizadas. Com a evolução do ciclo, doses de 100 e $150 \mathrm{~kg} \mathrm{ha}^{-1}$ de N proporcionaram maior acúmulo de MSB do que sob $50 \mathrm{~kg} \mathrm{ha}^{-1}$, que por sua vez superou o observado para plantas, sem adubação nitrogenada (Figura 2).

Verificou-se, portanto, que a participação de assimilados na cebola alterou conforme a dose de $\mathrm{N}$ aplicado. Pode-se inferir que plantas fertilizadas com dose superior a $100 \mathrm{~kg} \mathrm{ha}^{-1} \mathrm{de} \mathrm{N}$, apresentaram-se bem nutridas em $\mathrm{N}$, de modo que ao iniciarem a formação do órgão de reserva (bulbo), tiveram neste o principal dreno, determinando reduções no incremento de MSPA. Por outro lado, quanto menor a dose de $\mathrm{N}$ fornecida, menor foi o incremento de MSB (Figura 2) e mais tardio a desaceleração no acúmulo de MSPA, que, aliás, não ocorreu na testemunha (dose zero) e permitiu a estas plantas apresentarem MSPA em quantidade semelhante à observada em plantas fertilizadas (Figura 1). Amarelecimento das plantas cultivadas com 0 e $50 \mathrm{~kg} \mathrm{ha}^{-1} \mathrm{de}$ $\mathrm{N}$ foi observado após iniciar a formação do bulbo.

Com base nas curvas de acúmulo de MSPA de plantas fertilizadas com dose igual ou superior a $100 \mathrm{~kg} \mathrm{ha}^{-1} \mathrm{de} \mathrm{N}(\mathrm{Fi}-$ gura 1), sugere-se três fases para explicar o crescimento da cebola: fase 1 , da semeadura aos 50 DAS; fase 2, de 51 a 110 DAS e fase 3 de 111 a 150 DAS. Entretanto, doses crescentes de $\mathrm{N}$ avaliadas promoveram respostas diferenciadas das plantas quanto ao acúmulo de MSPA (Figura 1). Na fase 1, para todas as doses de $\mathrm{N}$, foram constatados pequenos incrementos na MSPA e ausência de sinais de bulbificação. Na fase 2 , houve desenvolvimento distinto de plantas. A partir dos 70 DAS, a aplicação do nitrogênio, em qualquer dose estudada, promoveu incrementos na MSPA superiores ao observado em plantas não 
adubadas com N. Enquanto aos 90 DAS, plantas fertilizadas com $\mathrm{N}$ não diferiram entre si, aos 110 DAS as diferenças entre as curvas aumentaram, observandose maiores incrementos na MSPA à medida que aumentou a dose de $\mathrm{N}$ aplicada. A partir dos 110 DAS, houve início de desaceleração no acúmulo de MSPA para as doses acima de $50 \mathrm{~kg} \mathrm{ha}^{-1}$ de $\mathrm{N}$, caracterizando a fase 3. Em plantas não adubadas com $\mathrm{N}$ não ocorreu a desaceleração e o acúmulo permaneceu constante conforme já comentado.

Com relação ao $\mathrm{K}$, verificou-se que a influência do incremento na dose aplicada não foi tão expressiva sobre o acúmulo de MSPA quanto observado para o N. As curvas de acúmulo de MSPA em resposta às doses de $\mathrm{K}$ foram muito semelhantes e a partir de 130 DAS plantas adubadas ou não com K não diferiram em quantidade de MSPA (Figura 3). No entanto, a aplicação de K proporcionou maior MSB do que plantas não fertilizadas em K. A partir de 90 DAS, plantas fertilizadas com K não diferiram entre si mas acumularam maior MSB do que plantas não fertilizadas $\left(\mathrm{Y}_{\mathrm{K} 0}=1,8355 \mathrm{x}^{2}\right.$ $254,8 \mathrm{x}+9101,58 \mathrm{R}^{2}=1 * * ; \mathrm{Y}_{\mathrm{K} 75}=2,031 \mathrm{x}^{2}$ $-268,05 \mathrm{x}+8993,83 \mathrm{R}^{2}=0,99 * * ; \mathrm{Y}_{\mathrm{K} 150}=$ $2,278 x^{2}-318,97 x+11431,31 R^{2}=0,99 * * e$ $\mathrm{Y}_{\mathrm{K} 225}=2,176 \mathrm{x}^{2}-294,12 \mathrm{x}+10092,55 \mathrm{R}^{2}=$ $0,99 * *)$. Na colheita, plantas fertilizadas apresentaram $14,73 \mathrm{~g}$ por planta enquanto plantas não fertilizadas com K 12,18 g por planta.

Quanto ao efeito da população de plantas, verificou-se que a partir de 110 DAS, plantas de cebola acumularam quantidades diferentes de MSPA. Até 90 DAS, a MSPA não diferiu entre populações de 60 a 108 plantas $\mathrm{m}^{-2}$, apresentando média de 3,45 g planta $^{-1}$ (Figura 4). Verifica-se, na mesma figura, que quanto maior a população de plantas, a desaceleração no acúmulo de MSPA foi mais precoce. Para a maior população avaliada, 108 plantas $\mathrm{m}^{-2}$, a partir de 115 DAS a taxa de incremento de MSPA foi fortemente reduzida em relação ao período de 60 a 115 DAS. Por outro lado, para a menor população avaliada, 60 plantas $\mathrm{m}^{-2}$, o mesmo comportamento não foi observado, constatando-se, ainda a partir de 115 DAS, incrementos significativos na MSPA, que possibilitam, inclusive, diferir-se, aos 130 e $150 \mathrm{DAS}$, em quan-

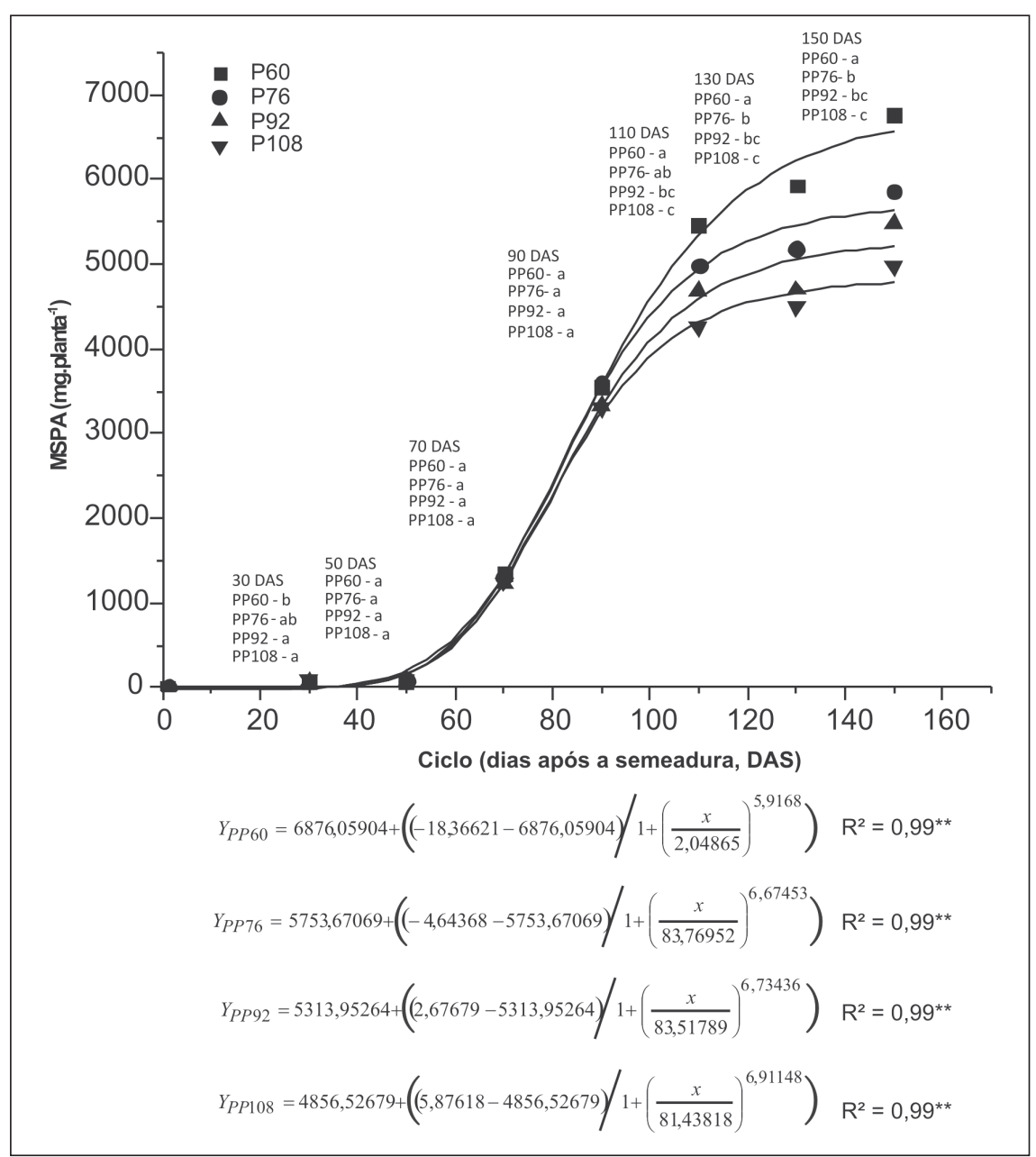

Figura 4. Acúmulo de matéria seca da parte aérea (MSPA) de plantas de cebola no decorrer do ciclo, em função da população de plantas. (aerial part dry mass (MSPA) of onion plants in elapsing of the cycle, in function of the plant density). Jaboticabal, UNESP, 2006.

tidades acumuladas de MSPA da população de 76 plantas $\mathrm{m}^{-2}$ (Figura 4).

Kanton et al. (2002) também verificaram reduções significativas na MSPA de plantas de cebola cultivadas sob elevadas populações de plantas. Os autores estudaram cebolas transplantadas nas populações de plantas de 37,04; 44,44; 51,28; 55,56; 66,67; 76,92; $100 \mathrm{e}$ 156,25 plantas $\mathrm{m}^{-2}$. Observaram um aumento de $20 \%$ na MSPA com a redução na população de plantas inferiores a 76 plantas $\mathrm{m}^{-2}$ e atribuíram ao resultado a menor competição pelos fatores do meio.

No final do ciclo, as quantidades de MSPA de plantas cultivadas sob populações de 60, 76, 92 e 108 plantas $\mathrm{m}^{-2}$ foram, respectivamente, de 6,88; 5,64; 5,21 e 4,79 g planta $^{-1}$ (Figura 4). Os acúmulos de MSPA descritos nas quatro populações avaliadas refletem diretamen- te o potencial de produção do bulbo da cebola, medida na MSB. Plantas de cebola sob menor competição intraespecífica, menor densidade populacional, apresentaram maior MSPA e, também, por consequiência, maior MSB.

A partir de 130 DAS, a quantidade de MSB foi diferente entre as populações avaliadas (Figura 5), possivelmente retratando a diferença observada para MSPA (Figura 4) aos 110 DAS. Aos 150 DAS, a MSB foi maior em cultura com 60 plantas $\mathrm{m}^{-2}$ do que sob plantios com estandes iguais ou superiores a 92 plantas $\mathrm{m}^{-2}$ (Figura 5). Contudo, a constatada maior capacidade em alocar matéria seca no bulbo por uma planta de cebola, sob menor densidade populacional, não está associada diretamente com a obtenção de maior produtividade. Esta depende do produto resultante de massa 
do bulbo e densidade populacional. Por outro lado, a rentabilidade da cultura, sim, está associada diretamente com as curvas de acúmulo de MSPA e de MSB descritas pela cebola em função da população. Menor adensamento possibilitou maior bulbo (MSB) e consequentemente maiores percentagens da produção total de bulbos da cultura nas classes 3 e 3 cheio, as quais são comercialmente mais valorizadas no mercado in natura. Por outro lado, quando a cebola destina-se à indústria de picles, o aumento na população de plantas mostrou ser pertinente.

As máximas produtividades obtidas neste trabalho, 72,02 $\mathrm{t} \mathrm{ha}^{-1}$ para a 'Optima' e 78,91 t ha-1 para a 'Superex', foram bastante superiores àquelas tradicionalmente obtidas pelos produtores de São José do Rio Pardo no sistema de transplante de mudas, que está ao redor de $45 \mathrm{t} \mathrm{ha}^{-1}$ de bulbos e aquelas alcançadas nos demais estados produtores do Brasil, média nacional 15 a $17 \mathrm{t}$ $\mathrm{ha}^{-1}$ de bulbos, segundo Boeing (2002).

\section{AGRADECIMENTOS}

Os autores agradecem à FAPESP pelo auxílio à pesquisa concedido (Proc 2003/13794-3), ao CNPQ pelas bolsas de produtividade em pesquisa e de doutorado, respectivamente ao primeiro e segundo autores, às empresas Agristar do Brasil Ltda. e Takii do Brasil Ltda. nas pessoas de Maurício Coutinho Pellegrini e Eduardo Hideomi Seo, respectivamente, a Rosemari Teotônio Rodrigues, a Salete Anelise Nappi pela ajuda nos trabalhos de campo.

\section{REFERÊNCIAS}

BOEING G. 2002. Fatores que afetam a qualidade da cebola na agricultura familiar catarinense. Florianópolis: Instituto CEPA-SC. 88 p.

EMBRAPA. 1999. Sistema Brasileiro de Classificação de Solos. Rio de Janeiro: Embrapa Solos. 412p.

FONTES PCR; SILVA DJH. 2002. Métodos de produção de cebola. Informe Agropecuário 23: 28-35.

GUIMARÃES DR; TORRES L; DITTRICH RC. 1997. Viabilidade técnica da semeadura direta para a cultura da cebola. Agropecuária Catarinense 10: 57-61.

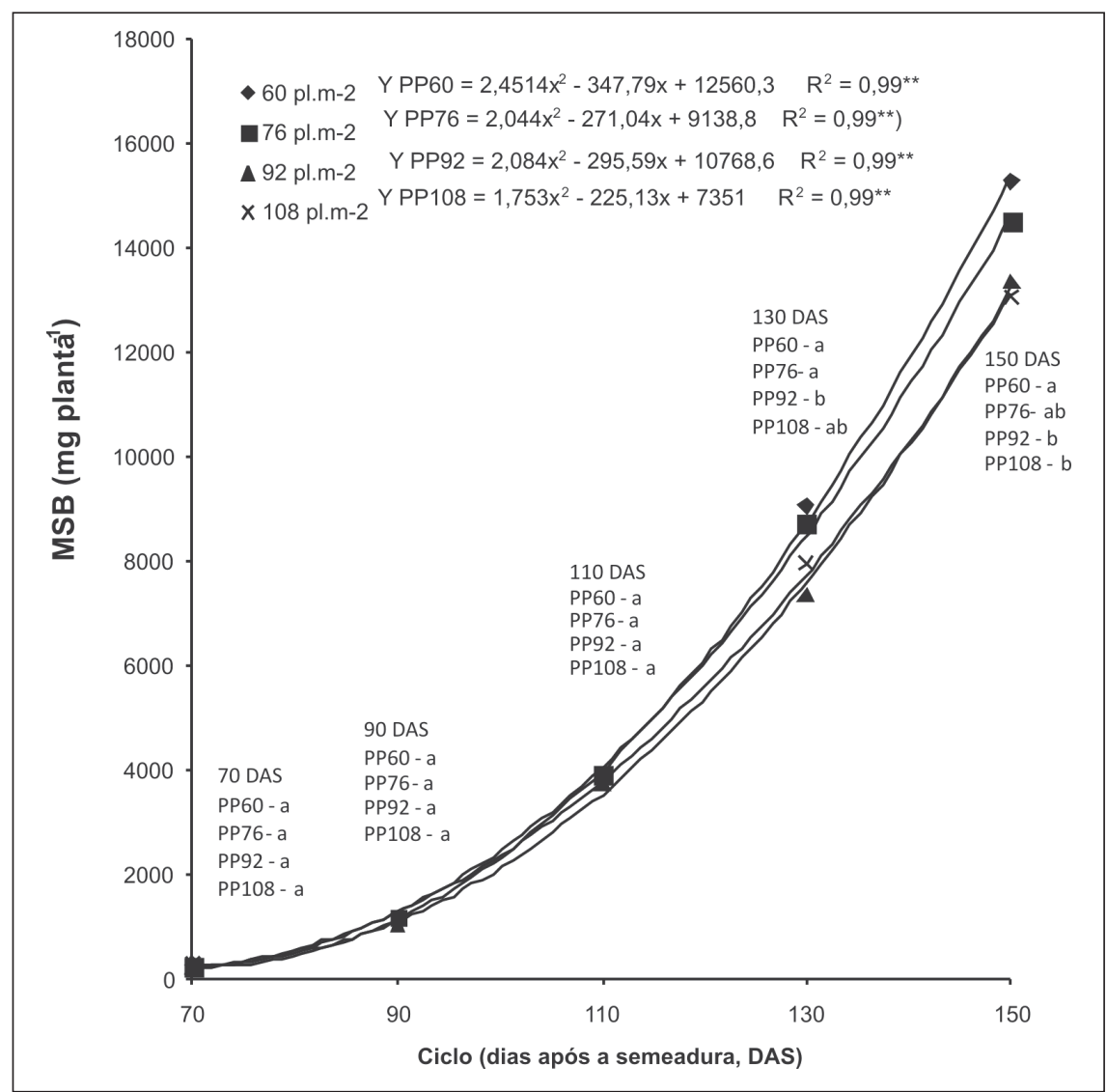

Figura 5. Acúmulo de matéria seca de bulbos (MSB) de plantas de cebola no decorrer do ciclo, em função da população de plantas. (bulb dry mass (MSB) of onion plants in elapsing of the cycle, in function of the plant density). Jaboticabal, UNESP, 2006.

HAAG HP; HOMA P; KIMOTO T. 1970. Nutrição mineral de hortaliças. VIII. Absorção de nutrientes pela cultura da cebola. Anais da Escola Superior de Agricultura "Luiz de Queiroz" 27: 143153.

KANTON RAL; ABBEY L; HILLA RG; TABIL MA; JAN ND. 2002. Density affects plant development and yield of bulb onion (Allium cepa L.) in northern Ghana. Journal of Vegetable Crop Production 8: 15-25.

LOUÉ A. 1978. The interaction of potassium with other growth factors, particularly with other nutrients. In: CONGRESS: POTASSIUM RESEARCH-REVIEW AND TRENDS, 11., 1978, Bern, Proceedings.... p. 407-434.

MENGEL K; KIRKBY EA. 1987. Principles of plant nutrition. Bern, International Potash Institute. 687p.

PÔRTO DRQ; CECÍLIO FILHO AB; MAY A; VARGAS PF. 2007. Acúmulo de macronutrientes pela cultivar de cebola Superex, estabelecida por semeadura direta. Ciência Rural 37: 949-955.

RESENDE GM; COSTA ND. 2005. Produtividade e armazenamento de cebola cv. Alfa Tropical cultivada em diferentes espaçamentos Horticultura Brasileira 23: 1010-1014.
TEI F; SCAIFE A; AIKMAN DP. 1996. Growth of lettuce, onion, and red beet. 1 . Growth analysis, light interception, and radiation use efficiency. Annals of Botany 78: 633-643.

TRANI PE; TAVARES M; SIQUEIRA WJ. 1996. Cebola (sistema de mudas). In: RAIJ B; CANTARELla H; QUAGGIO JA; FURLANI AMC. Recomendações de adubação e calagem para o estado de São Paulo, Campinas/SP: IAC. p. 176. (Boletim Técnico 100).

VIANELlO RL; ALVES AR. 1991. Meteorologia básica e aplicações. Viçosa, UFV. Imprensa Universitária. 449p.

VIDIGAL SM; PEREIRA PRG; SEDIYAMA CS; SEDIYAMA MAN; FONTES PCR. 2000. Produção de cebola influenciada por doses, fontes e parcelamento de nitrogênio em diferentes épocas de cultivo no verão. Horticultura Brasileira 18: 814-815.

WIEDENFELD R. 1994. Nitrogen rate and timming effects on onion growth and nutrient uptake in a subtropical climate. Subtropical Plant Science 46: 32-37. 